\title{
Quantitative Analysis of the Expression of Human N-myristoyltransferase 1 (hNMT-1) in Cancers
}

\author{
Lifeng Chen, Binbing Ling, Jane Alcorn and Jian Yang*
}

College of Pharmacy and Nutrition, University of Saskatchewan, 110 Science Place, Saskatoon, Saskatchewan S7N 5C9, Canada

\begin{abstract}
Human N-myristoyltransferase 1 (hNMT-1) catalyzes the covalent attachment of myristic acid to N-terminal glycine residues (myristoylation) of numerous protein substrates. Overexpression of hNMT-1 in colorectal and gallbladder cancers makes it a potential biomarker and drug design target for such cancers. In this study, we investigated hNMT-1 expression during the progression of eight different human cancers using quantitative RT-PCR. The study results showed that hNMT-1 was up-regulated in breast, colon, lung and ovarian cancers but not kidney, liver, prostate and thyroid cancers. This suggests a role for hNMT-1 as a biomarker for detection of breast, colon, lung and ovarian cancers. This study also suggests the available hNMT-1 inhibitors may be potential therapeutic agents against breast and lung cancers through all disease stages, although their use would likely be limited to early stage colon and ovarian cancers.
\end{abstract}

\section{INTRODUCTION}

Protein modification is an important component of genetic regulation. The structural alterations resulting from protein modification may regulate the biological activity, sub-cellular localization, stability, and turnover of proteins [1-5]. Unlike the common modifications (phosphorylation, nucleotidylation and glycosylation), myristoylation is a relatively rare type of acylation. Myristoylation involves the covalent attachment of myristic acid (C14:0) to the $\mathrm{N}$ terminal glycine residue of protein substrates via an amidic linkage [6-8]. Co- or post-translational myristoylation increases protein lipophilicity and facilitates the protein's association with cellular membranes and/or other hydrophobic protein domains $[9,10]$.

Protein myristoylation is catalyzed by a family of highly conserved enzymes, N-myristoyltransferases (E.C. 2.1.3.93). These enzymes are ubiquitously distributed in eukaryotic cells [6-10]. Previous biochemical and structural studies revealed that N-myristoyltransferases belong to the GCN5related $\mathrm{N}$-acetyltransferase superfamily and possess a pseudo 2-fold symmetry in their catalytic domains [11-13]. The Nterminal half is more conserved in amino acid residues and is responsible for the binding of myristoyl-coenzyme A (myristoyl-CoA). The C-terminal half has fewer conserved amino acid residues and is responsible for protein substrate recognition. N-myristoyltransferases follow an ordered bi-bi sequential catalytic mechanism (Fig. 1). Myristoyl-CoA binds to the enzymes first, followed by binding of the protein substrate to form a ternary complex. Upon completion of the reaction, coenzyme A (Co-A) is released prior to release of the myristoylated protein substrate. No covalent bonds are formed between myristoyl-CoA and the N-myristoyltransferases during the reaction [14].

*Address correspondence to this author at the College of Pharmacy and Nutrition, University of Saskatchewan, 110 Science Place, Saskatoon, Saskatchewan S7N 5C9, Canada; Tel: 306-966-6361; Fax: 306-966-6377; E-mail: jian.yang@usask.ca

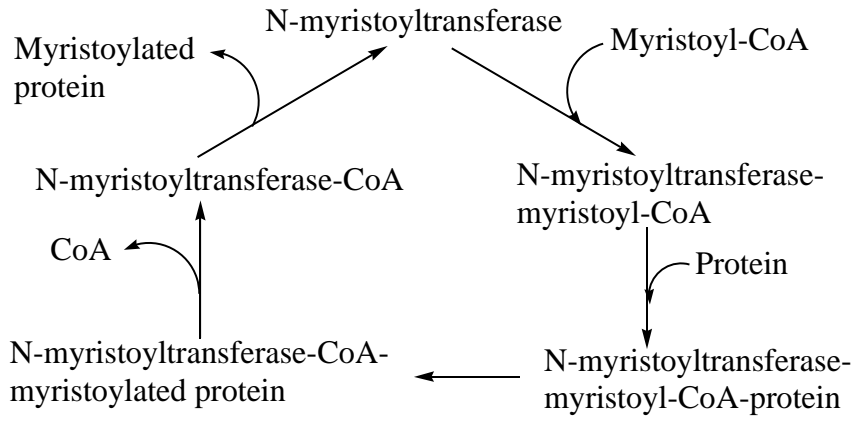

Fig. (1). Ordered bi-bi sequential catalytic mechanism for $\mathrm{N}$ myristoyltransferases. Myristoyl-CoA binds prior to the protein substrate and the release of CoA occurs before the release of the myristoylated protein substrate.

Human N-myristoyltransferase 1 (hNMT-1) is encoded by a single gene copy located on chromosome 17 (17q21.31) $[15,16]$. hNMT-1 protein substrate specificity can be broadly divided into two groups: signal transduction proteins such as the protein tyrosine kinases pp $60^{\mathrm{c}-\mathrm{src}}, \mathrm{pp} 60^{\mathrm{yes}}, \mathrm{pp} 56^{\mathrm{lck}}$, $\mathrm{pp} 59^{\mathrm{fyn} / \mathrm{syn}}$ and c-Abl, and viral proteins such as the HIV-1 and SIV Nef proteins and the HIV Pr53 ${ }^{\text {gag }}$ precursor [17-28]. hNMT-1's involvement in tumorgenesis was first reported with colon cancer where colorectal cancer cells demonstrated enhanced hNMT-1 expression and activity, as well as increased activity of its substrate pp60 ${ }^{\mathrm{c}-\mathrm{src}}[29,30]$. Furthermore, inhibition of $\mathrm{pp} 60^{\mathrm{c}-\mathrm{src}}$ myristoylation using $\mathrm{N}$ myristoyltransferase inhibitors depressed the colony formation of colonic cancer cell lines [29]. Subsequent reports indicated hNMT-1 upregulation in gallbladder and brain cancers $[31,32]$. Such studies identified hNMT-1 as a possible anti-cancer drug design target, which has promoted the development of several families of inhibitors [33-36]. Since substrates of hNMT-1 participate in different signal transduction pathways, abnormal expression and activity of hNMT-1 might be involved in the pathogenesis of other cancer types. In addition, no previous studies have addressed the 
Table 1. Patient Demographic Characteristics and Cancer Stage for the Origene TissueScan Oncology qPCR Cancer Survey Panel 96

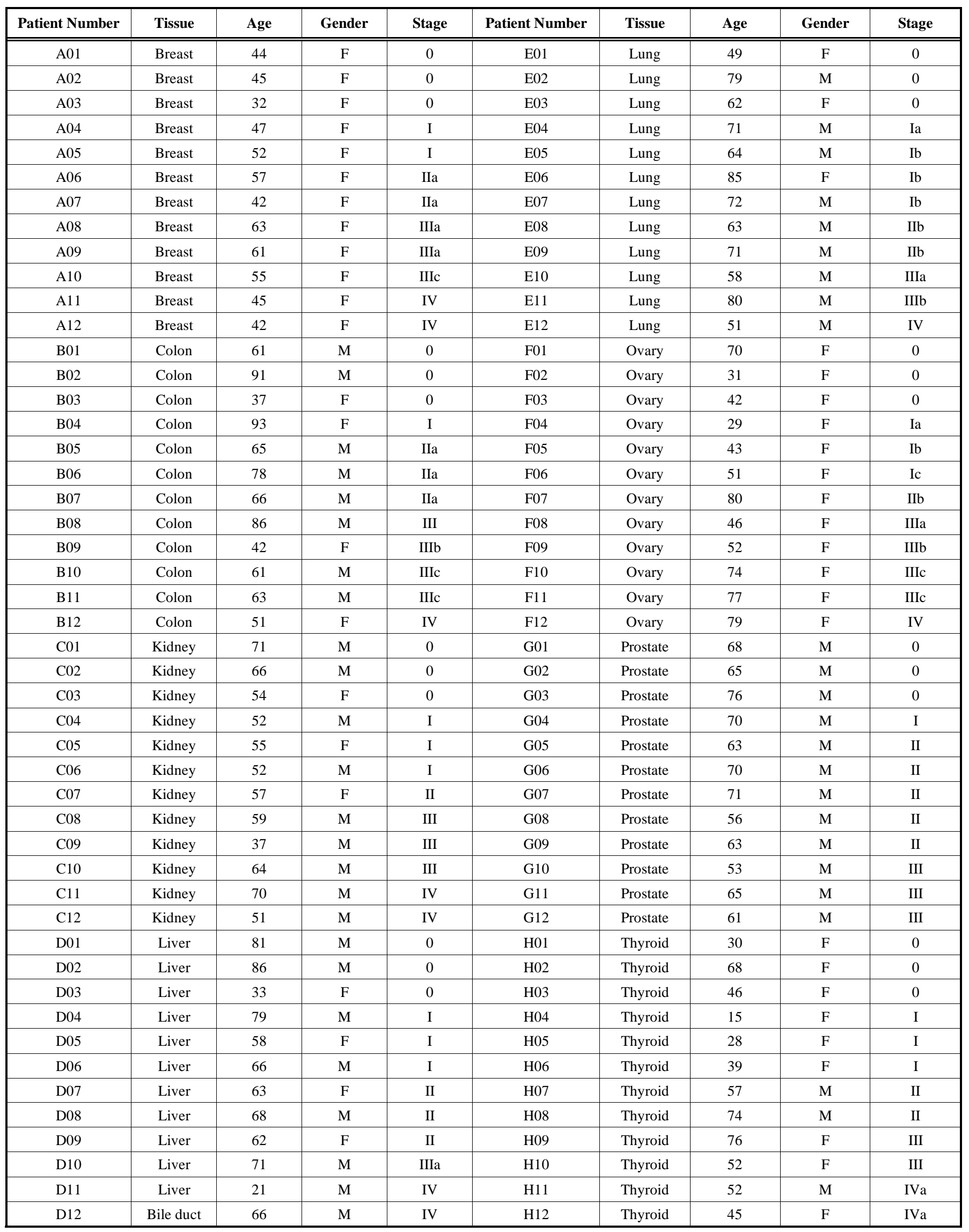


variations in hNMT-1 expression levels over the progression of human cancers. In order to investigate the role hNMT-1 plays in the progression of different cancer types, hNMT-1 mRNA expression levels were evaluated in a 96-patientsample cancer survey panel by quantitative RT-PCR in the current study.

\section{MATERIALS AND METHODOLOGY}

hNMT-1 mRNA expression levels were evaluated in an Origene 96-sample TissueScan Oncology qPCR Cancer Survey Panel (Table 1) by quantitative RT-PCR using an Applied Biosystems 7300 Real-Time PCR System (Foster City, California, USA). hNMT-1 expression was normalized to the internal control, $\beta$-actin in the different patients. Primer sequences (forward: GATGATGACAACATGTTCCGATTTGA-TT; reverse: GCCGGAGAGCCCACAAA) and the TaqMan probe (FAM-ATTCCCCGGAGTTTCT) for gene NMT1 (GenBank accession number: AF043324) encoding hNMT-1 were designed and synthesized by Applied Biosystems based on the ITS region. The TaqMan probe was labeled with FAM at 5'-end and non-fluorescent quencher at 3'-end. The quantitative RT-PCR reaction mixture consisted of TaqMan Gene Expression Master Mix (Applied Biosystems), $0.9 \mu \mathrm{M}$ of each primer for gene NMT1 and the gene encoding $\beta$-actin, and $0.9 \mu \mathrm{M}$ of the TaqMan probe. $30 \mu \mathrm{L}$ of PCR reaction mixture was added to each well of the 96smaple qPCR Cancer Survey Panel. The amplification was carried out under the following conditions: $2 \mathrm{~min}$ at $50^{\circ} \mathrm{C}, 10$ min at $95^{\circ} \mathrm{C}, 60$ cycles of $15 \mathrm{~s}$ at $95^{\circ} \mathrm{C}$, and finally $1 \mathrm{~min}$ at $60^{\circ} \mathrm{C}$. The expression level of hNMT-1 was averaged in each disease stage and normalized to $\beta$-actin. The fold-difference in mRNA expression at each disease stage was determined by comparison to expression levels in normal patients (stage 0 , expression level set as 1). Unpaired t-test with Welch's correction between the hNMT-1 expression levels in normal and cancer patients for each cancer type was performed with GraphPad Prism 4.0 (GraphPad Software, San Diego, California, USA) when possible, with $\alpha=0.05$.

\section{RESULTS AND DISCUSSION}

To evaluate whether hNMT-1 could be used as a biomarker for human cancers, the mRNA expression level of hNMT-1 was quantitatively analyzed in eight different cancer types. As shown in Table 2, hNMT-1 mRNA expression

Table 2. The Average Fold Difference (FD) in hNMT-1 mRNA Expression Levels in Patients with Cancer Relative to Patients Without Cancer

\begin{tabular}{|c|c|c|}
\hline Cancer Type & FD & P-value \\
\hline \hline Breast & 3.7 & 0.032 \\
\hline Colon & 3.1 & 0.001 \\
\hline Kidney & 1.0 & 0.986 \\
\hline Liver & 0.9 & 0.742 \\
\hline Lung & 2.3 & 0.003 \\
\hline Ovarian & 1.8 & 0.012 \\
\hline Prostate & 1.2 & 0.253 \\
\hline Thyroid & 1.3 & 0.225 \\
\hline
\end{tabular}

levels were significantly elevated by an average of $3.7,3.1$, 2.3 and 1.8 fold in breast, colon, lung and ovarian cancers, respectively, $(\mathrm{P}=0.032, \mathrm{P}=0.001, \mathrm{P}=0.003$ and $\mathrm{P}=0.012$ for breast, colon, lung and ovarian cancer, respectively) but not in kidney, liver, prostate and thyroid cancers. These data implicate a role for hNMT-1 as a biomarker for early detection of human breast, colon, lung and ovarian cancers and suggest that hNMT-1 inhibitors could be used as potential therapeutic agents against such cancers.

To obtain a preliminary impression on whether the expression of hNMT-1 varies with cancer progression, we also wished to compare mRNA expression levels at each cancer stage (Fig. 2). However, the small sample size associated with the panel precluded a complete analysis, one that must await a larger scale screening study. Nonetheless, we have gleaned valuable information from our limited analysis, which will provide an important reference for the design of future screenings. In breast and lung cancers, we noted that hNMT-1 expression generally increases with disease progression, such that by stage IV hNMT-1 expression was 4.5and 3.5-fold higher than normal subjects for breast and lung cancer, respectively. These data suggest hNMT-1 may contribute to the development and progression of breast and lung cancer, and further identified potential role of hNMT-1 inhibitors as effective therapeutics against breast and lung cancer throughout disease progression.

In colon cancer, upregulation of hNMT-1 was greatest in early stage cancer ( $\sim 6.5$-fold higher in stage I) (only one 93 year old patient; larger scale screening needed) relative to late stage cancer $(\sim 3.5$-fold increase in stage IV). These data suggest use of hNMT-1 inhibitors as potential therapeutic agents against colon cancer, particularly during early stage progression. This conclusion is consistent with the previous studies that showed N-myristoyltransferase inhibitors depressed the colony formation of colonic cancer cell lines [29]. In ovarian cancer, hNMT-1 expression demonstrated a general increase with disease progression until stage IIIa (only one patient; larger scale screening needed) and returned to normal expression levels by stage IV. Although the reason for this return to normal expression levels in late stage ovarian cancer is not known, the data does indicate that hNMT-1 inhibitors might be effective for treatment of early stage ovarian cancer. Furthermore, as a biomarker, early detection of hNMT-1 expression might be necessary for effective hNMT-1 inhibitor based therapy. Interestingly, we noticed a 2-fold decrease and a 3-fold increase in the hNMT1 expression at stage IV liver cancer and stage III thyroid cancer, respectively, without changes at other stages of diseases' progression. The panel was based on two stage IV liver cancer and two stage-III thyroid cancer patient samples, and this observation could simply represent a spurious result due to the low sample number. Further studies are required to clarify this outcome.

\section{CONCLUSION}

In this study, we showed that hNMT-1 expression was up-regulated in human breast, colon, lung and ovarian cancers, which suggests its use as a potential biomarker for these cancers. Furthermore, the available hNMT-1 inhibitors may be potential therapeutic agents against breast and lung cancers through all stages of cancer progression, while their 


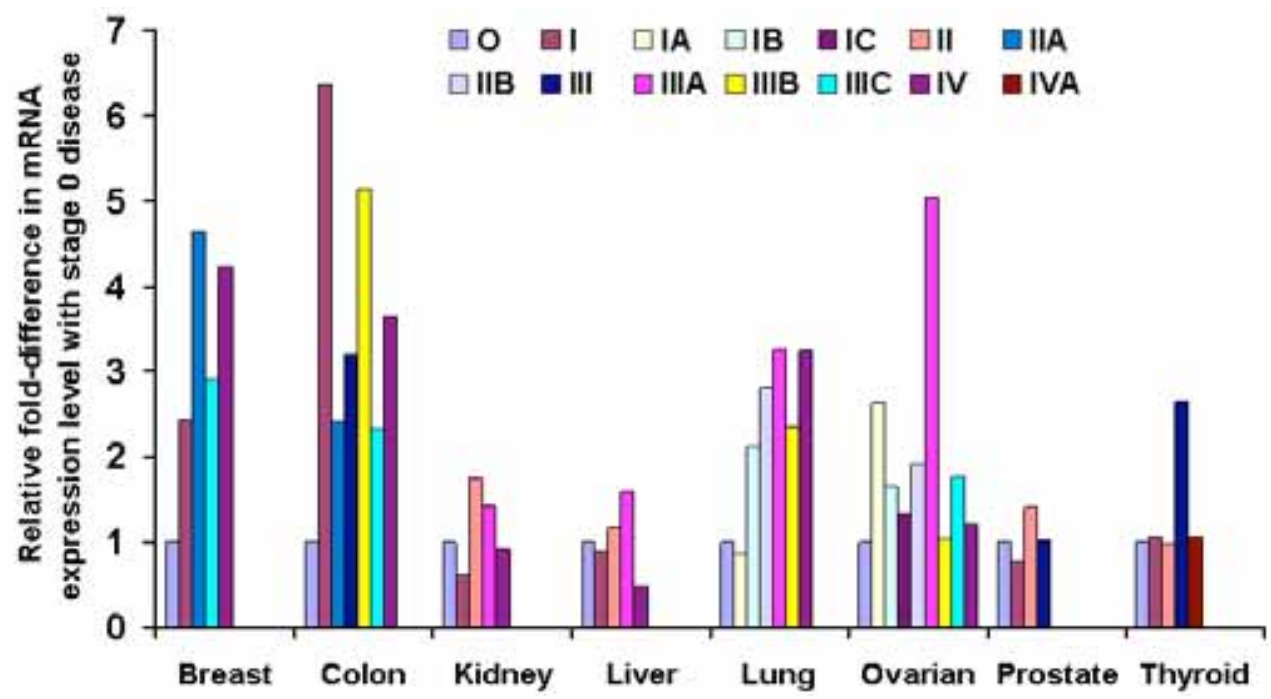

Fig. (2). Relative fold-difference in hNMT-1 mRNA expression at different stages of human cancer progression (hNMT-1 mRNA expression was screened in the Origene 96-patient-sample TissueScan Oncology qPCR Cancer Survey Panel).

use would likely be limited to early stage colon and ovarian cancers.

\section{ACKNOWLEDGEMENT}

This work was supported by a research grant from the Cancer Research Society Inc. of Canada.

\section{REFERENCES}

[1] Luthra M, Balasubramanian D. Nonenzymatic glycation alters protein structure and stability. A study of two eye lens crystallins. J Biol Chem 1993; 268: 18119-27.

[2] Hurley JH, Dean AM, Sohl JL, Koshland DE Jr, Stroud RM. Regulation of an enzyme by phosphorylation at the active site. Science 1990; 249: 1012-6.

[3] David SSM, Haley BE. ATP nucleotidylation of creatine kinase. Biochemistry 1999; 38: 8492-500.

[4] Parodi AJ. Protein glycosylation and its role in protein folding. Annu Rev Biochem 2000; 69: 69-93.

[5] O'Shea JJ, Kanno Y, Chen X, Levy DE. Cell signaling. Stat acetylation-a key facet of cytokine signaling? Science 2005; 307: 217-8

[6] Resh MD. Myristylation and palmitylation of Src family members: the fats of the matter. Cell 1994; 76: 411-3.

[7] Boutin JA. Myristoylation. Cell Signal 1997; 9: 15-35.

[8] Raju RV, Datla RS, Moyana TN, Kakkar R, Carlsen SA, Sharma RK. N-myristoyltransferase. Mol Cell Biochem 2000; 204: 135-55.

[9] Raju RV, Magnuson BA, Sharma RK. Mammalian myristoyl CoA: protein N-myristoyltransferase. Mol Cell Biochem 1995; 149: 191202.

[10] Robbins SM, Quintrell NA, Bishop JM. Myristoylation and differential palmitoylation of the HCK protein-tyrosine kinases govern their attachment to membranes and association with caveolae. Mol Cell Biol 1995; 15: 3507-15.

[11] Bhatnagar RS, Futterer K, Farazi TA, et al. Structure of Nmyristoyltransferase with bound myristoyl-CoA and peptide substrate analogs. Nat Struct Biol 1998; 5: 1091-7.

[12] Sogabe S, Masubuchi M, Sakata K, et al. Crystal structures of Candida albicans N-myristoyltransferase with two distinct inhibitors. Chem Biol 2002; 9: 1119-28.

[13] Weston SA, Camble R, Colls J, et al. Crystal structure of the antifungal target N-myristoyl transferase. Nat Struct Biol 1998; 5: 21321.

[14] Bhatnagar RS, Jackson-Machelski E, McWherter CA, Gordon JI. Isothermal titration calorimetric studies of Saccharomyces cerevisiae myristoyl-CoA:protein N-myristoyltransferase. J Biol Chem 1994: 269: 11045-53.

[15] Duronio RJ, Reed SI, Gordon JI. Mutations of human myristoylCoA:protein N-myristoyltransferase cause temperature-sensitive myristic acid auxotrophy in Saccharomyces cerevisiae. Proc Nat Acad Sci USA 1992; 89: 4129-33.

[16] Peseckis SM, Resh MD. Fatty acyl transfer by human N-myristyl transferase is dependent upon conserved cysteine and histidine residues. J Biol Chem 1994; 269: 30888-92.

[17] Carr SA, Biemann K, Shoji S, Parmelee DC, Titani K. nTetradecanoyl is the NH2-terminal blocking group of the catalytic subunit of cyclic AMP-dependent protein kinase from bovine cardiac muscle. Proc Natl Acad Sci USA 1982; 79: 6128-31.

[18] Zha J, Weiler S, Oh KJ, Wei MC, Korsmeyer SJ. Posttranslational $\mathrm{N}$-myristoylation of BID as a molecular switch for targeting mitochondria and apoptosis. Science 2000; 290: 1761-5.

[19] Schultz AM, Henderson LE, Oroszlan S, Garber EA, Hanafusa H. Amino terminal myristylation of the protein kinase p60src, a retroviral transforming protein. Science 1985; 227: 427-9.

[20] Marchildon GA, Casnellie JE, Walsh KA, Krebs EG. Covalently bound myristate in a lymphoma tyrosine protein kinase. Proc Natl Acad Sci USA 1984; 81: 7679-82.

[21] Nadler MJ, Harrison ML, Ashendel CL, Cassady JM, Geahlen RL. Treatment of $\mathrm{T}$ cells with 2-hydroxymyristic acid inhibits the myristoylation and alters the stability of p56lck. Biochemistry 1993; 32: 9250-5.

[22] van't Hof W, Resh MD. Rapid plasma membrane anchoring of newly synthesized $\mathrm{p} 59^{\mathrm{Fyn}}$ : selective requirement for $\mathrm{NH}_{2}$-terminal myristoylation and palmitoylation at cysteine-3. J Cell Biol 1997; 136: $1023-35$.

[23] Aitken A, Cohen P, Santikarn S, et al. Identification of the NH2terminal blocking group of calcineurin B as myristic acid. FEBS Lett 1982; 150: 314-8.

[24] Schultz AM, Tsai SC, Kung HF, Oroszlan S, Moss J, Vaughan M. Hydroxylamine-stable covalent linkage of myristic acid in G0 alpha, a guanine nucleotide-binding protein of bovine brain. Biochem Biophys Res Commun 1987; 146: 1234-9.

[25] Bryant ML, Heuckeroth RO, Kimata JT, Ratner L, Gordon JI. Replication of human immunodeficiency virus 1 and Moloney murine leukemia virus is inhibited by different heteroatom-containing analogs of myristic acid. Proc Natl Acad Sci USA 1989; 86: 86559.

[26] Hammes SR, Dixon EP, Malim MH, Cullen BR, Greene WC. Nef protein of human immunodeficiency virus type 1: evidence against its role as a transcriptional inhibitor. Proc Natl Acad Sci USA 1989; 86: 9549-53.

[27] Marc D, Masson G, Girard M, van der Werf S. Lack of myristoylation of poliovirus capsid polypeptide VP0 prevents the formation of virions or results in the assembly of noninfectious virus particles. J Virol 1990; 64: 4099-107.

[28] Gottlinger HG, Sodroski JG, Haseltine WA. Role of capsid precursor processing and myristoylation in morphogenesis and infectivity 
of human immunodeficiency virus type 1. Proc Natl Acad Sci USA 1989; 86: 5781-5.

[29] Shoji S, Kurosawa T, Inoue H, Funakoshi T, Kubota Y. Human cellular src gene product: identification of the myristoylated pp60csrc and blockage of its myristoyl acylation with $\mathrm{N}$-fatty acyl compounds resulted in the suppression of colony formation. Biochem Biophys Res Commun 1990; 173: 894-901.

[30] Magnuson BA, Raju RV, Moyana TN, Sharma RK. Increased Nmyristoyltransferase activity observed in rat and human colonic tumors. J Natl Cancer Inst 1995; 87: 1630-5.

[31] Rajala RV, Radhi JM, Kakkar R, Datla RS, Sharma RK. Increased expression of $\mathrm{N}$-myristoyltransferase in gallbladder carcinomas. Cancer 2000; 88: 1992-9.

[32] Lu Y, Selvakumar $\mathrm{P}$, Ali $\mathrm{K}$, et al. Expression of $\mathrm{N}$ myristoyltransferase in human brain tumors. Neurochem Res 2005; 30: 9-13.
[33] French KJ, Zhuang Y, Schrecengost RS, Copper JE, Xia Z, Smith CD. Cyclohexyl-octahydro-pyrrolo[1,2-a]pyrazine-based inhibitors of human N-myristoyltransferase-1. J Pharmacol Exp Ther 2004; 309: 340-7.

[34] Takemune N, Misumi S, Furuishi K, Shoji S. Blockage of HIV-1 production through inhibition of proviral DNA synthesis by N,Odidecanoyl serinal dimethylacetal. IUBMB Life 1999; 48: 311-5.

[35] Takamune N, Hamada H, Misumi S, Shoji S. Novel strategy for anti-HIV-1 action: selective cytotoxic effect of Nmyristoyltransferase inhibitor on HIV-1-infected cells. FEBS Lett 2002; 527: 138-42.

[36] Dimmock JR, Jha A, Zello GA, et al. 3,5-bis(phenylmethylene)-1(N-arylmaleamoyl)-4-piperidones: a novel group of cytotoxic agents. J Enzyme Inhib Med Chem 2003; 18: 325-32.

Received: November 04, 2008

Revised: January 06, 2009

Accepted: February 10, 2009

(C) Chen et al.; Licensee Bentham Open.

This is an open access article licensed under the terms of the Creative Commons Attribution Non-Commercial License (http://creativecommons.org/licenses/by-nc/3.0/) which permits unrestricted, non-commercial use, distribution and reproduction in any medium, provided the work is properly cited. 